\title{
ANALISIS RISIKO KESELAMATAN DAN KESEHATAN KERJA PADA PETUGAS KESEHATAN INSTALASI GAWAT DARURAT RUMAH SAKIT AKADEMIK UGM
}

\section{Oktaviana Zahratul Putri', Tengku Mohamed Ariff Bin Raja Hussin ${ }^{2}$, Heru Subaris Kasjono ${ }^{3}$}

\author{
${ }^{1,2}$ Institute for Comunity Development and Quality Of Life, University Sultan Zainal \\ Abidin, Kampus Gong Badak 21300 Terengganu, Malaysia. \\ Email: 1'oktavianazahraa@gmail.com, ${ }^{2}$ tg_mariff@unisza.edu.my \\ ${ }^{3}$ Politeknik Kesehatan Negeri Yogyakarta, Jl. Tata Bumi No. 3, Banyuraden, Gamping. \\ Email: ${ }^{3}$ kherusubaris@gmail.com
}

\begin{abstract}
ABSTRAK
Undang-undang No.44 Tahun 2009 tentang Rumah Sakit pasal 7 ayat 1, bahwa salah satu persyaratan Rumah Sakit adalah harus memenuhi unsur keselamatan dan kesehatan kerja. Laporan National Safety Council (NSC) tahun 1988 menunjukkan terjadinya kecelakaan di RS $41 \%$ lebih besar dari pekerja di industri lain. Kasus yang sering terjadi di antaranya tertusuk jarum atau needle stick injury (NSI), terkilir, sakit pinggang, tergores/terpotong, luka bakar, penyakit dan infeksi. Salah satu upaya pencegahan terjadinya kecelakaan kerja adalah dengan melakukan analisis risiko. Tujuan dari studi adalah untuk melakukan analisis risiko keselamatan dan kesehatan kerja petugas kesehatan dan administrasi di Rumah Sakit Akademik UGM. Metode yang digunakan yaitu observasi dan wawancara kepada petugas instalasi gawat darurat, membuat job hazard analisis, kemudian dilakukan analisis risiko dengan pendekatan AS/NZS 4360: 2004 dan menilai dengan tabel W.T.Fine. Hasil studi menunjukkan bahwa faktor bahaya di instalasi gawat darurat terdiri dari bahaya fisik, biologi, ergonomi, perilaku, dan psikologis. Faktor bahaya fisik merupakan yang dominan yaitu jarum suntik (benda tajam) yang berdampak luka tusuk dan tertular penyakit menular dari pasien. Nilai risiko tertinggi bahaya fisik dan biologi pada proses pekerjaan pemasangan infus pada pasien sebesar 150 (tinggi) mengharuskan adanya perbaikan secara teknis. Nilai risiko ini didapatkan apabila telah melakukan rekomendasi pengendalian dari peneliti.
\end{abstract}

Kata kunci : Analisis risiko, AS/NZS 4360, rumah sakit

\begin{abstract}
Law No.44 of 2009 on Hospital Article 7 paragraph 1, that one of the requirements of the Hospital is occupational safety and health. The National Safety Council (NSC) report of 1988 showed an accident in hospitals $41 \%$ larger than workers in other industries. Common cases include needle stick injury or needle stick injury (NSI), sprains, back pain, scratches/cuts, burns, disease, and infection. One of the preventions of work accident is by doing risk analysis. The purpose of
\end{abstract}


the study was to analyze the occupational health and safety risk of health and administration personnel at UGM Academic Hospital. The method used was observation and interview to emergency department officer, make job hazard analysis, then do risk analysis with the approach of AS / NZS 4360: 2004 and assess with table W.T.Fine. The results indicated that hazard factors in the emergency department were physical, biological, ergonomic, behavioral, and psychological hazards. The physical hazard factors were the dominant of the hypodermic needle (sharps) that impact puncture wounds and contracting infectious diseases from patients. The highest risk value of physical and biological hazards was in the infusion process in patients, ie 150 (high category), which requires technical improvement. This risk value was obtained if it has done the recommendation of control from the researcher.

Keywords: Risk analysis, AS/NZS 4360, hospital

\section{PENDAHULUAN}

Rumah sakit merupakan institusi pelayanan kesehatan yang kompleks, padat profesi dan padat modal. Pelayanan rumah sakit menyangkut berbagai fungsi pelayanan, pendidikan, penelitian dan juga mencakup berbagai tindakan maupun disiplin medis. Rumah Sakit adalah tempat kerja yang memiliki potensi terhadap terjadinya kecelakaan kerja. Bahan mudah terbakar, gas medik, radiasi pengion, dan bahan kimia merupakan potensi bahaya yang memiliki risiko kecelakaan kerja. Oleh karena itu, Rumah Sakit membutuhkan perhatian khusus terhadap keselamatan dan kesehatan pasien, staf dan umum (Sadaghiani, 2001 dalam Omrani dkk., 2015).

Undang-undang No.44 Tahun 2009 tentang Rumah Sakit pasal 7 ayat 1, bahwa "Rumah Sakit harus memenuhi persyaratan lokasi, bangunan, prasarana, sumber daya manusia, kefarmasian, dan peralatan", persyaratan-persyaratan tersebut salah satunya harus memenuhi unsur Keselamatan dan Kesehatan Kerja di dalamnya. Rumah Sakit yang tidak memenuhi persyaratan-persyaratan tersebut tidak diberikan izin mendirikan, dicabut atau tidak diperpanjang izin operasional Rumah Sakit (pasal 17) (MENKES RI, 2009).

Keselamatan dan kesehatan kerja bertujuan melindungi pekerja atas keselamatannya agar dapat meningkatkan produktifitas nasional. Menjamin semua pekerja yang berada di tempat kerja menggunakan serta merawat sumber produksi secara aman dan efisien (MENKES, 2009).

Hasil laporan National Safety Council (NSC) tahun 1988 menunjukkan bahwa terjadinya kecelakaan di RS $41 \%$ lebih besar dari pekerja di industri lain. Kasus yang sering terjadi di antaranya tertusuk jarum atau needle stick injury $(N S I)$, terkilir, sakit pinggang, tergores/terpotong, luka bakar, penyakit infeksi dan lain-lain (Kemenkes, 2007).

Risk Management Standard AS/NZS 4360:2004 menyatakan bahwa analisis risiko bersifat pencegahan terhadap terjadinya kerugian maupun accident. Mengelola risiko harus dilakukan secara berurutan langkah-langkahnya yang nantinya bertujuan untuk membantu dalam pengambilan keputusan yang lebih baik dengan melihat risiko dan dampak yang kemungkinan ditimbulkan.

Instalasi gawat darurat merupakan pelayanan yang memerlukan pelayanan 
segera, yaitu cepat, tepat dan cermat untuk mencegah kematian dan kecacatan (Kemenkes, 2016). Instalasi gawat darurat rumah sakit akademik UGM memiliki kejadian kecelakaan terbanyak bila dibandingkan dengan unit kerja lain. Kasus kecelakaan di Instalasi Gawat Darurat Rumah Sakit Akademik UGM sebanyak 9 orang dengan 4 jenis proses pekerjaan atau tindakan. Sebagai Rumah Sakit yang menerapkan peduli keselamatan dan kesehatan kerja petugas kesehatan maupun administrasi, peneliti tertarik untuk mengambil tema Analisis Risiko Keselamatan dan Kesehatan Kerja Pada Petugas Kesehatan Instalasi Gawat Darurat Rumah Sakit Akademik UGM dengan pendekatan AS/NZS dan tabel penilaian W.T.Fine.

\section{METODE PENELITIAN}

Penelitian ini menggunakan metode pendekatan AS/NZS 4360:2004 Tentang
Risk Management dengan tabel penilaian risiko W.T.Fine. Lokasi penelitian dilakukan di Rumah Sakit Akademik UGM Yogyakarta. Waktu pelaksanaan penelitian pengambilan sampel dan data pada bulan Maret sampai Juli 2017. Informan dari penelitian ini adalah petugas kesehatan di Instalasi Gawat Darurat Rumah Sakit Akademik UGM. Data primer diambil dengan cara observasi dan wawancara kepada petugas kesehatan instalasi gawat darurat Rumah Sakit. Validasi data dilakukan kepada petugas instalasi Keselamatan dan Kesehatan Kerja RSA UGM. Data sekunder diambil dari rekap data kecelakaan yang pernah terjadi di RSA UGM. Pengumpulan data dilakukan dengan cara observasi dan wawancara kemudian dihitung menggunakan analisis semi-kuanitatif sesuai dengan metode AS/NZS 4360:2004 dan penilaian risiko W.T.Fine. dan menentukan tingkat risiko menggunakan Tabel 1.

Tabel 1. Penentuan Tingkat Risiko

\begin{tabular}{lll}
\hline $\begin{array}{c}\text { Tingkat } \\
\text { risiko }\end{array}$ & Kategori & \multicolumn{1}{c}{ Tindakan } \\
\hline$>350$ & Sangat tinggi & $\begin{array}{l}\text { Aktifitas dihentikan sampai risiko bisa dikurangi hingga mencapai } \\
\text { batasan yang dibolehkan atau diterima }\end{array}$ \\
$180-350$ & Prioritas 1 & Perlu pengendalian sesegera mungkin \\
$70-180$ & Tinggi & Mengharuskan adanya perbaikan secara teknis \\
$20-70$ & Prioritas 3 & Perlu diawasi dan diperhatikan secara berkesinambungan \\
$<20$ & diterima & Intensitas yang menimbulkan risiko dikurangi seminimal mungkin
\end{tabular}

Penilaian risiko dengan metode AS/NZS 4360 dilakukan dengan menilai risiko yang ada. Pada tahap awal menggunakan job hazard analisis dari observasi dan wawancara. Penilaian risiko pekerjaan menggunakan Tabel W.T.Fine setelah dilakukan analisis risiko pekerjaan.
Nilai risiko Basic Risk yaitu nilai risiko tanpa mempertimbangkan pengendalian yang sudah dilakukan rumah sakit. Existing risk yaitu nilai risiko yang mempertimbangkan pengendalian yang sudah dilakukan rumah sakit. Residual Risk yaitu nilai risiko yang mempertimbangkan rekomendasi pengendalian dari peneliti. Nilai tingkat 
risiko didapatkan dari perkalian consequences, Exposure dan Likelihood yang terdapat dalam tabel W.T.Fine.

\section{HASIL DAN PEMBAHASAN}

\section{Gambaran Umum}

Penelitian ini dilaksanakan di

Rumah Sakit Akademik UGM khususnya di Instalasi Gawat Darurat. Rumah Sakit UGM memiliki 36 kasus kecelakaan kerja pada periode Januari 2015 - Juli 2017.
Kasus kecelakaan kerja terbanyak terdapat di Instalasi Gawat Darurat. Jumlah kasus kecelakaan di Instalasi Gawat Darurat sebanyak 9 kasus kecelakaan.

\section{Kasus kecelakaan yang berkaitan dengan proses pekerjaan di Instalasi Gawat Darurat}

Kasus kecelakaan yang terdapat pada instalasi gawat darurat rumah sakit disajikan di dalam Tabel 2.

Tabel 2. Kasus Kecelakaan Yang Berkaitan dengan Proses Pekerjaan Di Instalasi Gawat Darurat

\begin{tabular}{lcc}
\hline \multicolumn{1}{c}{ Jenis Proses Pekerjaan } & $\begin{array}{c}\text { Jumlah kasus } \\
\text { (orang) }\end{array}$ & $\begin{array}{c}\text { Persentase } \\
(\mathbf{\%})\end{array}$ \\
\hline Proses pengambilan sampel darah & 2 & 22,2 \\
Pemasangan infus pasien & 3 & 33,4 \\
Perjalanan pergi atau pulang kerja & 1 & 11,1 \\
Injeksi obat pada pasien & 2 & 22,2 \\
Proses menjahit luka & 1 & 11,1 \\
\hline Jumlah & $\mathbf{9}$ & $\mathbf{1 0 0}$ \\
\hline
\end{tabular}

Jenis pekerjaan yang pernah mengalami kecelakaan di instalasi gawat darurat meliputi proses pengambilan sampel darah, pemasangan infus pasien, perjalanan pergi dan pulang kerja (kecelakaan lalulintas), proses injeksi obat kepada pasien dan proses penjahitan luka pada pasien. Proses pekerjaan yang mengalami kecelakaan terbanyak yaitu proses pemasangan infus yaitu sebanyak 3 kasus $(33,4 \%)$ dari 9 kasus.

\section{Penilaian Risiko dengan metode AS/NZS 4360:2004 Proses Pekerjaan Pengambilan Sampel Darah pada pasien}

Tabel 3. Pengendalian Risiko Pekerjaan Pengambilan Sampel Darah

\begin{tabular}{|c|c|c|c|}
\hline $\begin{array}{l}\text { Jenis } \\
\text { pekerjaan }\end{array}$ & $\begin{array}{l}\text { Bahaya dan } \\
\text { Dampak }\end{array}$ & $\begin{array}{l}\text { Pengendalian yang ada } \\
\text { di Rumah Sakit }\end{array}$ & $\begin{array}{l}\text { Rekomendasi pengendalian } \\
\text { dari Peneliti }\end{array}$ \\
\hline \multirow[t]{6}{*}{$\begin{array}{l}\text { Mengambil } \\
\text { darah pasien }\end{array}$} & $\begin{array}{l}\text { Fisik menggunakan } \\
\text { jarum suntik dan luka } \\
\text { tusuk jarum suntik }\end{array}$ & $\begin{array}{l}\text { Alat Pelindung Diri dan } \\
\text { Standar } \quad \text { Prosedur } \\
\text { Operasional (SPO). }\end{array}$ & $\begin{array}{l}\text { 1. Tidak melakukan } \\
\text { pengambilan sampel sendiri, } \\
\text { harus menambah personil }\end{array}$ \\
\hline & & & $\begin{array}{l}\text { 2. Melakukan tindakan sesuai } \\
\text { SPO. }\end{array}$ \\
\hline & $\begin{array}{lr}\text { Biologi } & \text { kontak } \\
\text { dengan darah } & \text { pasien }\end{array}$ & $\begin{array}{ll}\text { Alat Pelindung } & \text { Diri dan } \\
\text { Standar } & \text { Prosedur }\end{array}$ & $\begin{array}{l}\text { 1. Selalu menyertakan safety box } \\
\text { saat melakukan tindakan }\end{array}$ \\
\hline & $\begin{array}{l}\text { dan tertular penyakit } \\
\text { menular (Hepatitis, } \\
\text { HIV dan AIDS) }\end{array}$ & Operasional & $\begin{array}{l}\text { 2. Menghilangkan tahap } \\
\text { recapping pada SPO di ganti } \\
\text { dengan langsung membuang } \\
\text { jarum ke dalam Safety box }\end{array}$ \\
\hline & $\begin{array}{ll}\text { Perilaku, } & \text { tidak } \\
\text { menggunakan } & \text { APD }\end{array}$ & 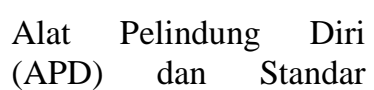 & $\begin{array}{l}\text { 1. Memberikan sosialisai dampak } \\
\text { dari tidak menggunakan APD }\end{array}$ \\
\hline & $\begin{array}{lr}\text { dan luka } & \text { tusuk dan } \\
\text { mudah } & \text { tertular }\end{array}$ & Prosedur Operasional & $\begin{array}{l}\text { 2. Mewajibkan semua petugas } \\
\text { medis memahami dan mentaati }\end{array}$ \\
\hline
\end{tabular}




\begin{tabular}{|c|c|c|c|}
\hline \multirow{3}{*}{$\begin{array}{l}\text { Jenis } \\
\text { pekerjaan }\end{array}$} & $\begin{array}{l}\text { Bahaya dan } \\
\text { Dampak }\end{array}$ & $\begin{array}{l}\text { Pengendalian yang ada } \\
\text { di Rumah Sakit }\end{array}$ & $\begin{array}{l}\text { Rekomendasi pengendalian } \\
\text { dari Peneliti }\end{array}$ \\
\hline & $\begin{array}{l}\text { penyakit menular } \\
\text { Hepatitis, AIDS, dan } \\
\text { HIV }\end{array}$ & & $\begin{array}{l}\text { tahap-tahap pekerjaan yang ada } \\
\text { di SPO }\end{array}$ \\
\hline & $\begin{array}{l}\text { Ergonomi } \\
\text { membungkuk saat } \\
\text { pengambilan darah } \\
\text { pasien (postur } \\
\text { janggal) dan nyeri } \\
\text { otot atau low back } \\
\text { pain }\end{array}$ & $\begin{array}{l}\text { Standar } \\
\text { Operasional }\end{array}$ & $\begin{array}{l}\text { 1. Memberikan penyuluhan } \\
\text { tentang bahaya low back pain. } \\
\text { 2. Menyediakan Kasur atau bed } \\
\text { yang fleksibel bisa di naik dan } \\
\text { turunkan }\end{array}$ \\
\hline
\end{tabular}

Tabel 3 menjelaskan tentang bahaya dan dampak dari proses pekerjaan pengambilan sampel darah. Menjelaskan pengendalian yang sudah ada di Rumah Sakit Akademik UGM dan rekomendasi pengendalian dari peneliti. Data tersebut digunakan untuk mendapatkan nilai risiko sesuai dengan metode AS/NZS 4360:2004. Nilai risiko pekerjaan pengambilan sampel darah dijelaskan pada Tabel 4.

Tabel 4. Nilai Risiko Pekerjaan Pengambilan Sampel Darah

\begin{tabular}{clccc}
\hline \multirow{2}{*}{$\begin{array}{c}\text { Jenis } \\
\text { pekerjaan }\end{array}$} & Bahaya & Basic Risk & $\begin{array}{c}\text { Existing } \\
\text { Risk }\end{array}$ & Residual Risk \\
\cline { 3 - 5 } Mengambil & Fisik & 500 & 300 & 60 \\
darah pasien & Biologi & 500 & 300 & 45 \\
& Perilaku & 450 & 135 & 30 \\
& Ergonomi & 100 & 60 & 18 \\
\hline
\end{tabular}

Pada pekerjaan pengambilan sampel darah pasien memiliki satu tahap pekerjaan yaitu mengambil darah pasien. Pengambilan darah pasien memiliki bahaya fisik menggunakan jarum suntik yang berdampak tertusuk jarum suntik. Bahaya biologi yaitu kontak dengan darah pasien yang berdampak tertular penyakit Hepatitis, AIDS, dan HIV. Bahaya perilaku yaitu tidak menggunakan alat pelindung diri yang berdampak mudah tertular penyakit Hepatitis, AIDS, dan HIV. Pada bahaya fisik, biologi dan bahaya perilaku apabila menerapkan rekomendasi pengendalian dari peneliti dapat menurunkan tingkat risiko menjadi 60, 45, dan 30 (prioritas 3) yaitu perlu diawasi dan diperhatikan secara berkesinambungan.

Bahaya ergonomi yaitu membungkuk saat pengambilan darah pasien (postur janggal) yang berdampak nyeri otot atau low back pain. Pada bahaya ergonomi apabila menerapkan rekomendasi pengendalian dari peneliti dapat menurunkan tingkat risiko menjadi 18 (diterima) yaitu intensitas yang menimbulkan risiko dikurangi seminimal mungkin.

\section{Proses Pekerjaan Pemasangan Infus Pada Pasien}

Pengendalian risiko pekerjaan pemasangan infus dapat dilihat pada Tabel 5. 
Tabel 5. Pengendalian Risiko Pekerjaan Pemasangan infus

\begin{tabular}{|c|c|c|c|}
\hline Jenis pekerjaan & Bahaya dan Dampak & $\begin{array}{l}\text { Pengendalian yang } \\
\text { ada di Rumah } \\
\text { Sakit }\end{array}$ & $\begin{array}{l}\text { Rekomendasi pengendalian dari } \\
\text { Peneliti }\end{array}$ \\
\hline \multirow[t]{5}{*}{$\begin{array}{l}\text { Penusukan } \\
\text { jarum ke vena }\end{array}$} & $\begin{array}{l}\text { Fisik menggunakan } \\
\text { jarum suntik dan luka } \\
\text { tusuk jarum suntik }\end{array}$ & 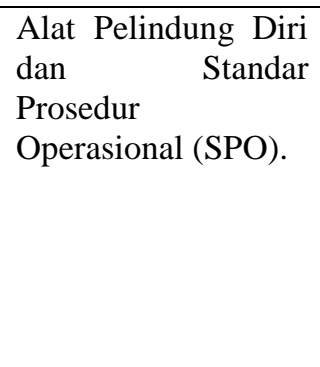 & $\begin{array}{l}\text { 1. Menenangkan pasien agar tidak } \\
\text { bergerak saat akan dilakukan } \\
\text { pemasangan jarum infus. } \\
\text { 2. Memberi pengarahan agar } \\
\text { melakukan pekerjaan sesuai } \\
\text { dengan SPO yang telah tersedia. } \\
\text { 3. Memberikan orientasi dan proses } \\
\text { kredensial kepada tenaga medis } \\
\text { tamu }\end{array}$ \\
\hline & $\begin{array}{l}\text { Biologi } \\
\text { dengan darah pasien } \\
\text { dan tertular penyakit } \\
\text { menular (Hepatitis, } \\
\text { HIV dan AIDS) }\end{array}$ & $\begin{array}{l}\text { Alat Pelindung Diri } \\
\text { dan Standar } \\
\text { Prosedur } \\
\text { Operasional }\end{array}$ & $\begin{array}{l}\text { 1. Mengganti sarung tangan apabila } \\
\text { terjadi sobek. } \\
\text { 2. Memberi pengarahan agar } \\
\text { melakukan pekerjaan sesuai } \\
\text { dengan SPO yang telah tersedia. } \\
\text { 3. Mewajibkan membawa safety box } \\
\text { saat akan melakukan tindakan }\end{array}$ \\
\hline & $\begin{array}{lr}\text { Perilaku, } & \text { tidak } \\
\text { menggunakan } \text { APD } \\
\text { dan luka tusuk dan } \\
\text { mudah } r \text { tertular } \\
\text { penyakit menular } \\
\text { Hepatitis, AIDS, dan }\end{array}$ & $\begin{array}{l}\text { Alat Pelindung Diri } \\
\text { (APD) dan Standar } \\
\text { Prosedur } \\
\text { Operasional }\end{array}$ & $\begin{array}{l}\text { 1. Memberikan sosialisai dampak } \\
\text { dari tidak menggunakan alat } \\
\text { pelindung diri } \\
\text { 2. Mewajibkan semua petugas medis } \\
\text { memahami dan mentaati tahap- } \\
\text { tahap pekerjaan yang ada di SPO }\end{array}$ \\
\hline & HIV & & $\begin{array}{l}\text { 3. Mewajibkan penggunaan APD } \\
\text { bagi petugas medis yang akan } \\
\text { melakukan tindakan ataupun } \\
\text { asisten yang membantu. }\end{array}$ \\
\hline & $\begin{array}{l}\text { Ergonomi } \\
\text { membungkuk saat } \\
\text { pengambilan darah } \\
\text { pasien (postur } \\
\text { janggal) dan nyeri } \\
\text { otot atau low back } \\
\text { pain }\end{array}$ & $\begin{array}{l}\text { Standar Operasional } \\
\text { Prosedur }\end{array}$ & $\begin{array}{l}\text { 1. Memberikan penyuluhan tentang } \\
\text { bahaya low back pain. } \\
\text { 2. Menyediakan Kasur atau bed yang } \\
\text { fleksibel bisa di naik dan turunkan }\end{array}$ \\
\hline \multirow[t]{2}{*}{ Merapikan alat } & $\begin{array}{l}\text { Fisik terdapat alat } \\
\text { suntik yang terbuka } \\
\text { dan luka tusuk jarum }\end{array}$ & $\begin{array}{l}\text { Alat Pelindung Diri } \\
\text { (APD), safety box } \\
\text { dan Standar } \\
\text { Prosedur } \\
\text { Operasional }\end{array}$ & $\begin{array}{l}\text { 1. Memberikan sosialisasi } \\
\text { penanganan jarum suntik bekas } \\
\text { kepada semua tenaga medis. } \\
\text { 2. Menghilangkan poin (reccapping) } \\
\text { pada SPO yang telah tersedia. } \\
\text { 3. Menambahkan poin menyediakan } \\
\text { atau membawa safety box pada } \\
\text { SPO. } \\
\text { 4. Membiasakan membuang jarum } \\
\text { bekas pakai langsung ke dalam } \\
\text { safety box }\end{array}$ \\
\hline & $\begin{array}{l}\text { Biologi terpapar darah } \\
\text { dan tertular penyakit } \\
\text { hepatitis, AIDS, HIV }\end{array}$ & $\begin{array}{l}\text { Alat Pelindung Diri } \\
\text { (APD), safety box } \\
\text { dan Standar } \\
\text { Prosedur } \\
\text { Operasional }\end{array}$ & $\begin{array}{l}\text { 1. Melakukan sosialisasi tentang } \\
\text { bahaya darah yang tercecer. } \\
\text { 2. Menyediakan perlak sebagai alas } \\
\text { tangan atau bagian tubuh yang } \\
\text { mau di pasang infus. } \\
\text { 3. Membiasakan membuang jarum } \\
\text { yang telah digunakan langsung ke } \\
\text { dalam safety box, tidak di letakkan } \\
\text { di kom kecil atau kotak peralatan. }\end{array}$ \\
\hline
\end{tabular}


Tabel 5 menjelaskan tentang bahaya dan dampak dari proses pekerjaan pemasangan infus. Menjelaskan pengendalian yang sudah ada di Rumah Sakit Akademik UGM dan rekomendasi pengendalian dari peneliti. Data tersebut digunakan untuk mendapatkan nilai risiko sesuai dengan metode AS/NZS 4360:2004. Nilai risiko pekerjaan pemasangan infus dijelaskan pada Tabel 6.

Tabel 6. Nilai Risiko Pekerjaan Pemasangan Infus

\begin{tabular}{llccc}
\hline \multirow{2}{*}{$\begin{array}{c}\text { Jenis } \\
\text { pekerjaan }\end{array}$} & \multicolumn{1}{c}{ Bahaya } & Basic Risk & Existing Risk & Residual Risk \\
\cline { 3 - 5 } Penusukan & Fisik & 500 & 300 & 150 \\
jarum ke vena & Biologi & 500 & 300 & 150 \\
& Perilaku & 450 & 135 & 30 \\
& Ergonomi & 100 & 60 & 18 \\
\hline Merapikan alat & Fisik & 1500 & 300 & 30 \\
& Biologi & 500 & 300 & 30 \\
\hline
\end{tabular}

Pada pekerjaan pemasangan infus pada pasien memiliki dua tahap pekerjaan yaitu penusukan jarum ke vena dan merapikan alat. Penusukan jarum ke vena pasien memiliki bahaya fisik menggunakan jarum suntik yang berdampak tertusuk jarum suntik. Bahaya biologi yaitu kontak dengan darah pasien yang berdampak tertular penyakit Hepatitis, AIDS, dan HIV. Pada bahaya fisik dan biologi apabila menerapkan rekomendasi pengendalian dari peneliti dapat menurunkan tingkat risiko menjadi 150 (Tinggi) yaitu mengharuskan adanya perbaikan secara teknis.

Bahaya perilaku yaitu tidak menggunakan alat pelindung diri yang berdampak mudah tertular penyakit Hepatitis, AIDS, dan HIV. Pada bahaya perilaku apabila menerapkan rekomendasi pengendalian dari peneliti dapat menurunkan tingkat risiko menjadi 30 (prioritas 3) yaitu perlu diawasi dan diperhatikan secara berkesinambungan.

$$
\text { Bahaya ergonomi yaitu }
$$

membungkuk saat penusukan jarum ke vena (postur janggal) yang berdampak nyeri otot atau low back pain. Pada bahaya ergonomi apabila menerapkan rekomendasi pengendalian dari peneliti dapat menurunkan tingkat risiko menjadi 18 (diterima) yaitu intensitas yang menimbulkan risiko dikurangi seminimal mungkin.

Tahap selanjutnya dari pekerjaan pemasangan infus yaitu merapikan alat. Merapikan alat memiliki bahaya fisik jarum suntik yang telah digunakan dalam pemasangan infus yang tidak langsung di buang ke dalam safety box. Dampak dari bahaya tersebut bukan hanya luka tusuk jarum suntik tetapi ada juga bahaya tertular penyakit menular yang di derita oleh pasien. Bahaya biologi dalam tahapan merapikan alat pun sama dengan bahaya fisik yaitu kontak dengan darah pasien dan dampaknya tertular penyakit hepatitis, HIV dan AIDS. Pada bahaya fisik dan biologi apabila menerapkan rekomendasi pengendalian dari peneliti dapat menurunkan tingkat risiko menjadi 30 (prioritas 3) yaitu perlu diawasi dan diperhatikan secara berkesinambungan.

\section{Proses pekerjaan Injeksi Obat Pada Pasien}

Proses pengendalian risiko pekerjaan injeksi obat pada pasien dapat dilihat pada Tabel 7 . 
Tabel 7. Pengendalian Risiko Pekerjaan Injeksi Obat Pada Pasien

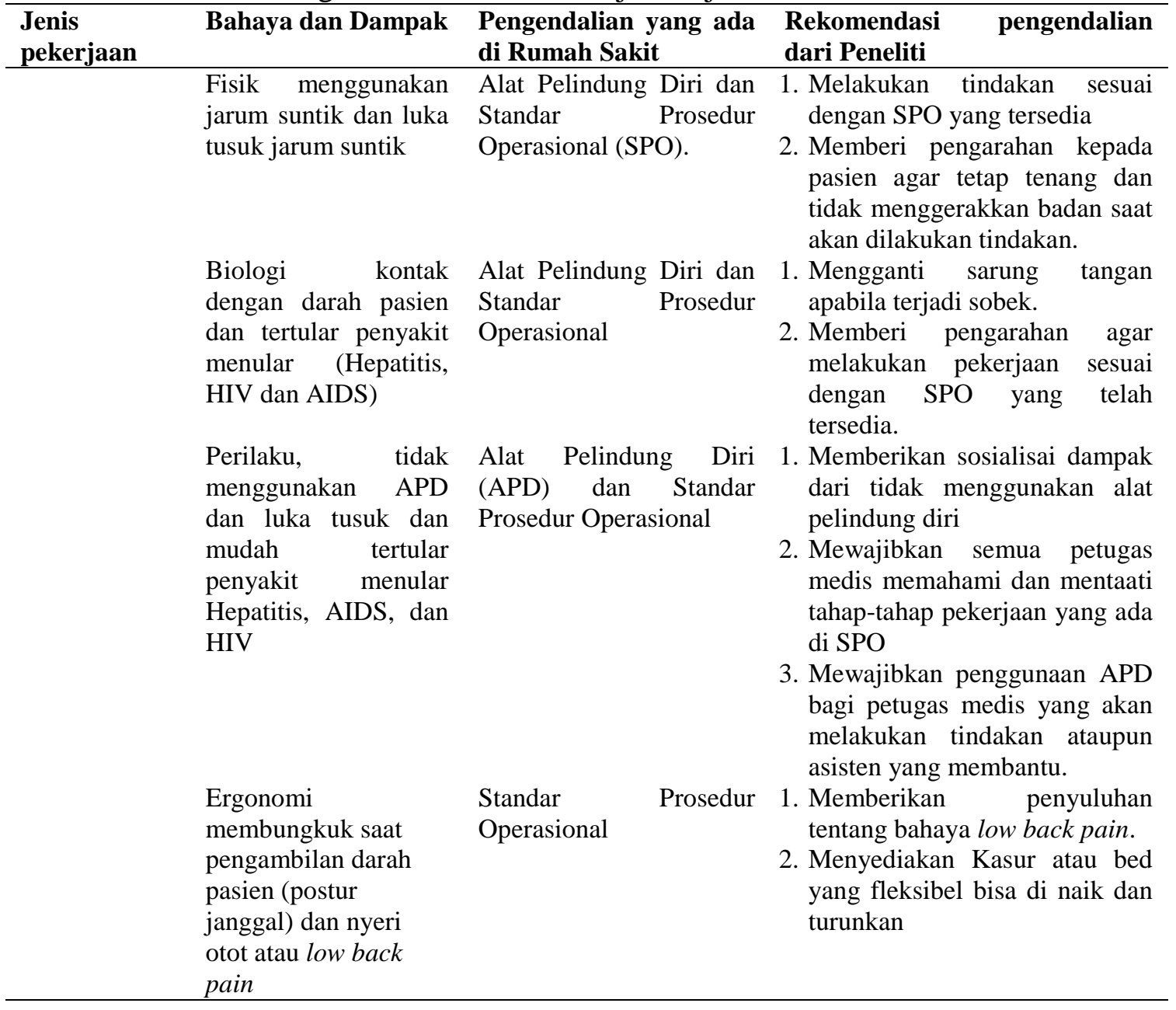

Tabel 7 menjelaskan tentang bahaya dan dampak dari proses pekerjaan injeksi obat. Menjelaskan pengendalian yang sudah ada di Rumah Sakit Akademik UGM dan rekomendasi pengendalian dari peneliti. Data tersebut digunakan untuk mendapatkan nilai risiko sesuai dengan metode AS/NZS 4360:2004. Nilai risiko pekerjaan injeksi obat pada pasien dijelaskan pada Tabel 8.

Tabel 8. Nilai Risiko Pekerjaan Injeksi Obat

\begin{tabular}{|c|c|c|c|c|}
\hline \multirow{2}{*}{$\begin{array}{c}\text { Jenis } \\
\text { pekerjaan }\end{array}$} & \multirow{2}{*}{ Bahaya } & \multicolumn{3}{|c|}{ Nilai Risiko } \\
\hline & & Basic Risk & Existing Risk & Residual Risk \\
\hline Penusukan & Fisik & 500 & 100 & 60 \\
\hline jarum ke vena & Biologi & 300 & 150 & 100 \\
\hline & Perilaku & 450 & 135 & 30 \\
\hline & Ergonomi & 100 & 60 & 18 \\
\hline
\end{tabular}

Pada pekerjaan injeksi obat pada pasien memiliki satu tahap pekerjaan yaitu penusukan jarum ke vena. Penusukan jarum ke vena pasien memiliki bahaya fisik menggunakan jarum suntik yang berdampak tertusuk jarum suntik.
Kebiasaan merecap jarum suntik merupakan pemicu dampak luka tusuk, yang seharusnya setelah selesai jarum bekas pakai dibuang ke dalam safety box. Bahaya perilaku yaitu tidak menggunakan alat pelindung diri yang berdampak 
mudah tertular penyakit Hepatitis, AIDS, dan HIV. Pada bahaya fisik dan perilaku apabila menerapkan rekomendasi pengendalian dari peneliti dapat menurunkan tingkat risiko menjadi 60 dan 30 (prioritas 3) yaitu perlu diawasi dan diperhatikan secara berkesinambungan.

Bahaya biologi yaitu kontak dengan darah pasien yang berdampak tertular penyakit Hepatitis, AIDS, dan HIV. Pada bahaya biologi dan bahaya perilaku apabila menerapkan rekomendasi pengendalian dari peneliti dapat menurunkan tingkat risiko menjadi 100 (Tinggi) yaitu mengharuskan adanya perbaikan secara teknis

Bahaya ergonomi yaitu membungkuk saat penusukan jarum ke vena (postur janggal) yang berdampak nyeri otot atau low back pain. Pada bahaya ergonomi apabila menerapkan rekomendasi pengendalian dari peneliti dapat menurunkan tingkat risiko menjadi 18 (diterima) yaitu intensitas yang menimbulkan risiko dikurangi seminimal mungkin.

\section{Proses pekerjaan menjahit luka pasien} Proses pengendalian risiko pekerjaan menjahit luka pasien dapat dilihat pada Tabel 9.

Tabel 9. Pengendalian Risiko Pekerjaan Menjahit Luka Pasien

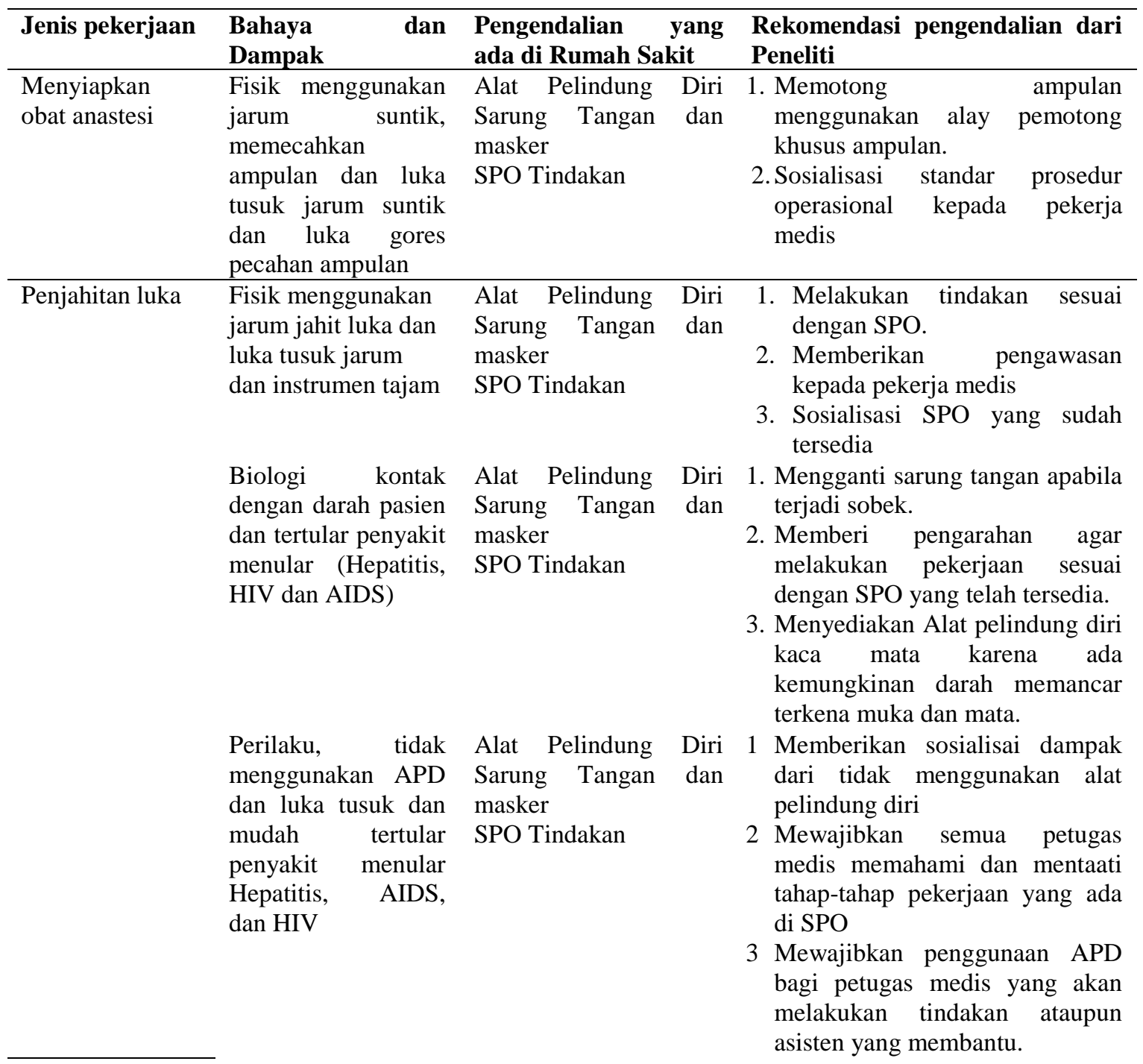




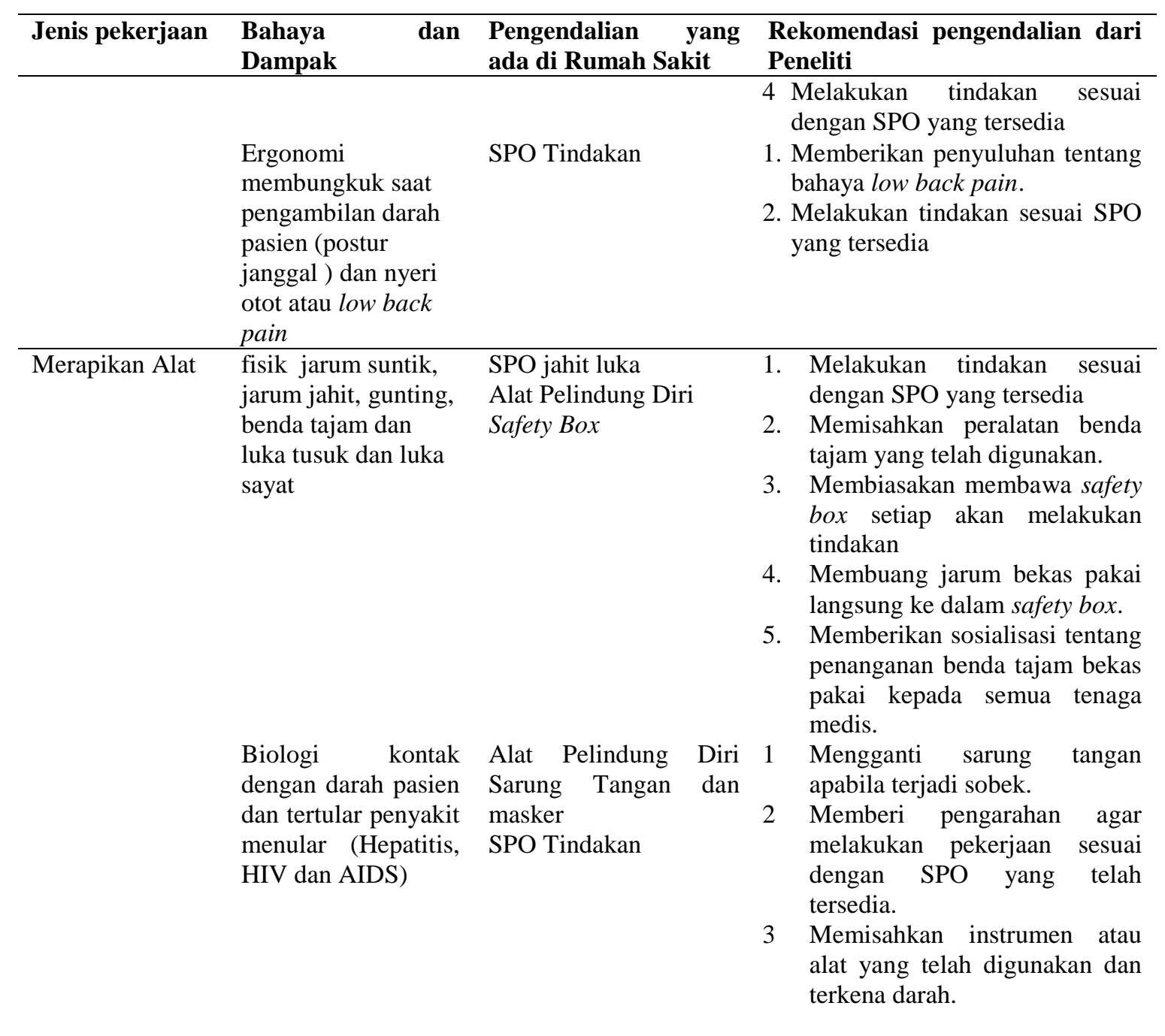

Tabel 9 menjelaskan tentang bahaya dan dampak dari proses pekerjaan menjahit luka pasien. Menjelaskan pengendalian yang sudah ada di Rumah Sakit Akademik UGM dan rekomendasi pengendalian dari peneliti. Data tersebut digunakan untuk mendapatkan nilai risiko sesuai dengan metode AS/NZS 4360:2004. Nilai risiko pekerjaan menjahit luka pasien dijelaskan pada Tabel 10.

Tabel 10. Nilai Risiko Pekerjaan Menjahit Luka

\begin{tabular}{|c|c|c|c|c|}
\hline \multirow{2}{*}{ Jenis Pekerjaan } & \multirow{2}{*}{ Bahaya } & \multicolumn{3}{|c|}{ Nilai risiko } \\
\hline & & Basic Risk & Existing Risk & Residual Risk \\
\hline $\begin{array}{l}\text { Menyiapkan obat } \\
\text { anastesi }\end{array}$ & Fisik & 540 & 180 & 90 \\
\hline \multirow[t]{4}{*}{ Penjahitan luka } & Fisik & 540 & 180 & 90 \\
\hline & Biologi & 540 & 270 & 60 \\
\hline & Perilaku & 540 & 270 & 90 \\
\hline & Ergonomi & 500 & 300 & 60 \\
\hline \multirow[t]{2}{*}{ Merapikan Alat } & Fisik & 540 & 135 & 45 \\
\hline & Biologi & 540 & 150 & 100 \\
\hline
\end{tabular}


Pada penjahitan luka pada pasien memiliki tiga tahap pekerjaan yaitu menyiapkan obat anastesi, penjahitan luka dan merapikan alat. Menyiapkan obat anastesi memiliki bahaya fisik menggunakan jarum suntik dan memecahkan ampulan. Dampaknya luka tusuk jarum dan luka gores pecahan ampulan. Pada bahaya fisik apabila menerapkan rekomendasi pengendalian dari peneliti dapat menurunkan tingkat risiko menjadi 90 (Tinggi) yaitu mengharuskan adanya perbaikan secara teknis.

Tahap pekerjaan ke dua yaitu penjahitan luka memiliki bahaya fisik yaitu jarum jahit luka atau jarum hecting. Dampaknya luka tusuk jarum hecting. pada bahaya fisik apabila menerapkan rekomendasi pengendalian dari peneliti dapat menurunkan tingkat risiko menjadi 90 (Tinggi) yaitu mengharuskan adanya perbaikan secara teknis.

Bahaya biologi dan bahaya perilaku yaitu kontak dengan darah pasien yang terjadi apabila tiba-tiba darah memancar ke arah wajah dan terkena mata, sedangkan petugas medis tidak menggunakan alat pelindung diri. Dampaknya sangat berbahaya apabila pasien memiliki riwayat penyakit menular. Petugas kesehatan memiliki kemungkinan tertular penyakit Hepatitis, AIDS, dan HIV. Pada bahaya biologi dan perilaku apabila menerapkan rekomendasi pengendalian dari peneliti dapat menurunkan tingkat risiko menjadi 60 dan 45 (prioritas 3) yaitu perlu diawasi dan diperhatikan secara berkesinambungan.

Bahaya ergonomi yaitu membungkuk pada saat menjahit luka (postur janggal) yang berdampak nyeri otot atau low back pain. Low back pain bisa terjadi karena terlalu lama membungkuk pada saat melakukan penjahitan luka. Pada bahaya ergonomi apabila menerapkan rekomendasi pengendalian dari peneliti dapat menurunkan tingkat risiko menjadi 18 (prioritas 3) yaitu perlu diawasi dan diperhatikan secara berkesinambungan.

Tahap selanjutnya dari pekerjaan penjahitan luka yaitu merapikan alat. Merapikan alat memiliki bahaya fisik jarum jahit luka (hecting) dan instrumen tajam yang telah digunakan dalam proses penjahitan luka. Jarum hecting tidak langsung di buang ke dalam safety box dan meletakkan jarum bekas pakai ke dalam tempat instrumen tajam. Dampak dari bahaya tersebut bukan hanya luka tusuk jarum suntik tetapi ada juga bahaya tertular penyakit menular yang di derita oleh pasien. Bahaya biologi dalam tahapan merapikan alat pun sama dengan bahaya fisik yaitu kontak dengan darah pasien dan dampaknya tertular penyakit hepatitis, HIV dan AIDS. Pada bahaya fisik apabila menerapkan rekomendasi pengendalian dari peneliti dapat menurunkan tingkat risiko menjadi 45 (prioritas 3) yaitu perlu diawasi dan diperhatikan secara berkesinambungan. Pada bahaya biologi tingkat risikonya turun menjadi 100 (Tinggi) yaitu mengharuskan adanya perbaikan secara teknis.

Hasil wawancara yang dilakukan peneliti terhadap petugas medis di instalasi gawat darurat bahwa bukan hanya bahaya fisik, kimia, biologi, ergonomi, dan perilaku saja. Bahaya psikologis juga terdapat di instalasi gawat darurat seperti tekanan atau intimidasi dari keluarga pasien yang tidak sabar menunggu penanganan dan pemeriksaan dokter atau perawat. Keluarga pasien mengancam petugas medis sampai mengakibatkan beberapa petugas medis mengalami trauma, ada pula yang sampai tidak masuk kerja di hari berikutnya. Bahaya psikologis ini belum ada penanganan dan belum ada laporan ke pihak instalasi keselamatan dan kesehatan kerja dikarenakan kejadiannya baru 
beberapa hari sebelum peneliti melakukan wawancara.

\section{KESIMPULAN}

Proses pekerjaan yang mengalami kecelakaan terbanyak yaitu proses pemasangan infus sebanyak 3 kasus $(33,4 \%)$ dari 9 kasus. Berdasarkan analisis yang dilakukan dengan pendekatan metode AS/NZS 4360:2004 didapatkan hasil bahwa bahaya fisik pada tiap pekerjaan berasal dari jarum suntik, jarum jahit, dan instrumen tajam. Bahaya biologi berasal dari darah pasien yang memiliki riwayat penyakit menular (Hepatitis, HIV dan AIDS). Bahaya perilaku berasal dari kebiasaan tidak menggunakan alat pelindung diri. Bahaya ergonomi berasal dari postur janggal. Bahaya psikologis juga ada di instalasi gawat darurat berasal dari keluarga pasien yang melakukan intimidasi atau tekanan kepada petugas medis. Apabila telah diterapkan rekomendasi pengendalian dari peneliti pada proses pengambilan sampel darah pasien, bahaya fisik memiliki nilai risiko tertinggi yaitu 60 (Prioritas 3) perlu diawasi dan diperhatikan secara berkesinambungan.

Pada proses pemasangan infus bahaya fisik dan biologi yang memiliki nilai risiko tertinggi yaitu 150 (Tinggi) mengharuskan adanya perbaikan secara teknis pada tahap penusukkan jarum ke vena. Injeksi obat pada pasien memiliki nilai risiko tertinggi pada bahaya biologi yaitu 100 (Tinggi) mengharuskan adanya perbaikan secara teknis. Pada proses pekerjaan terakhir yaitu menjahit luka pasien, nilai risiko tertinggi bahaya biologi pada tahap pekerjaan merapikan alat yaitu 100 (Tinggi) mengharuskan adanya perbaikan secara teknis.

\section{DAFTAR PUSTAKA}

Australian and New Zealand Standard on Risk Management 4360:2004.

Departemen Kesehatan RI., 2009, Standar Kesehatan dan Keselamatan Kerja di Rumah Sakit (K3 RS), Jakarta Indonesia.

Kementerian Kesehatan RI., 2007, Keputusan Menteri Kesehatan RI Nomor 432/MENKES/SK/IV/2007 tentang Pedoman Manajemen K3 di Rumah Sakit. Kementerian Kesehatan RI, Jakarta.

Kementerian Kesehatan RI. 2016. Data dan Informasi Profil Kesehatan Indonesia. Kementerian Kesehatan RI, Jakarta.

Omrani, A., Raeissi, P., Khosravizadeh, O., Mousavi, M., Kakemam, E., Sokhanvar, M., Najafi, B., 2015, Occupational Accidents among Hospital Staff, Client Centered Nursing Care, Vol. I, No. 2, pp. 97-101.

Surat Keputusan Menteri Kesehatan RI. No 856/MENKES/XI/2009. Tentang Standar IGD Rumah Sakit 